\title{
LEXICOGRAMMATICAL FEATURES IN JAPANESE ENGLISH: A STUDY OF FIVE SPEAKERS*
}

\author{
TOSHIKO YAMAGUCHI \\ University of Malaya, Malaysia \\ tyamag@um.edu.my
}

\begin{abstract}
Japanese English (JE) refers to the English spoken by Japanese citizens. This paper characterizes JE by examining its lexicogrammatical features produced by five speakers participating in experimental recordings. Drawing on the initiatives taken by Cogo and Dewey's seminal work (2012), this study presents nine lexicogrammatical features which are taken to be typical of JE. It is shown that one decisive factor in creating a new variant is the formation of an alternative form to its native counterpart and this mechanism is sourced from the speaker's multiple knowledge about two languages.
\end{abstract}

Keywords: creativity, Japanese English, lexicogrammatical features, multiple knowledge about two languages

\section{Introduction}

In this rapidly globalizing world, people from different countries and cultures communicate using English, a language which is not the mother tongue of the majority of those who speak it. Already in the 1980s, scholars witnessed a surge of non-native speakers of English which led the latter to outnumber the population of native speakers (Swan 1985; Strevens 1992: 27). For example, Swan (1985: 7) predicted the rise of "the new international English" which may, viewed from his EFL (English as a foreign language) perspective, shed many of the complexities of present-day native Englishes (e.g. British English, American English), such as in the tense system. In Japan, one learns English as a foreign language at school. Within the Japanese education system, English is a compulsory subject from the first year of junior high school (at which point pupils are 12-13 years old), but English has never become integral to the daily communication of Japanese nationals. The average Japanese citizen living in Japan with no outside contact has no need to communicate in English; Japanese is the language used to express oneself in all situations of everyday life (e.g. Browne and Wada 1998; Seargeant 2011; Abe 2013; Tsuneyoshi 2013; D'Angelo 2018). The need for communicative English is therefore restricted to specific domains, such as international business

* I am obliged to the second reviewer whose constructive comments were useful in revising an earlier version of this paper. 
and academia or tourism. Despite its limited use, English is becoming increasingly important in Japan, particularly in universities (McKenzie 2008). The number of non-Japanese students enrolled at Japanese universities has increased and they are not all fluent in Japanese. Lectures are now conducted in English at some institutions, and there are many student exchange programs. These changes are reflected in recent publications, but scholars have often discussed the ambivalent status of English as a global language, whether it is a foreign language, a lingua franca, an international language, or a language operating as a touchstone for social and cultural issues in contemporary Japan (on the last point, see Seargeant 2011). Crystal (2010: 17) remarked that the notion of English as a global language may not only refer to common features found across the globe but also to regional features specific to individual languages. For example, Yeah right is an expression of suspicion about the content preceding it (e.g. Of course I remember your name. Yeah right). To understand an example such as Let Paul fly us there. Yeah right, however, Crystal asserted that we need cultural knowledge about Paul (a radio personality who owned two private planes and crashed and survived twice), a piece of knowledge shared collectively by local people (New Zealanders in this case). Scholars and journalists generally express pessimism about the teaching of English in Japan. Friedman (2016) has expressed concern about the future of English in Japan since the teaching of the language has not undergone a paradigm shift, especially in terms of methodology and textbooks, which are still rooted in Meiji-era practice (1868-1912). In a similar vein, Tsuboya-Newell (2017) has reported on teachers' lack of communication skills in English in The Japan Times. What is interesting about Tsuboya-Newell's article is her point that environmental factors appear to be decisive in the acquisition of a foreign language, that is, the amount of exposure to an English-speaking environment rather than simply contact with a teacher. It is notable that the literature, as reviewed above, has a tendency to rely upon attitudinal, educational, or sociolinguistic standpoints to describe English in Japan. More than ten years ago, in a review of Stanlaw's (2004) monograph on Japanese English, which itself focuses on English loans that have entered the Japanese lexicon, Smith (2004) noted the lack of a linguistic study of the English used by native Japanese speakers. More recently, McKenzie reiterated the same point: there are "no detailed descriptions of ... linguistic features" (2013: 228).

This paper is an interim report on an ongoing project that currently has a sample of 25 Japanese speakers of English. We call the English produced by native Japanese speakers in spoken discourse "Japanese English" (JE). The main objective of this paper is to describe the linguistic features produced by five native Japanese speakers (four female, one male; J2, J3, J7, J8, and J12) talking about the topic of "weather" in an experimental setting. ${ }^{1}$ Section 2 explains how recordings were conducted and outlines the participants' linguistic and social

The letter "J" stands for a Japanese speaker who participated in the experimental recordings in 2016 and 2017. 
backgrounds. Based on the non-native features collected, Section 3 presents a preliminary analysis of lexicogrammatical features produced by these Japanese speakers. It is important to note at the outset that non-native features often, if not always, co-occurred with their native counterparts, forming two alternatives. JE speakers used these alternatives effectively to construct new meaning. Section 4 closes the paper by highlighting that a new variant can be identified when an alternative to an existing native form is created and this is sourced from the speaker's multiple knowledge about two languages - in this case, Japanese and English.

\section{Recordings: structure and participants}

The recordings were conducted in 2016 and 2017. Each recording comprised three components: (i) reading a short text, (ii) reading words, and (iii) speaking about given topics in English and Japanese. The first two components have already been the subject of an acoustic phonetic analysis (Yamaguchi and Pétursson 2018). The present study focuses on the third component, the free talks. There were three topics - (i) "my current situation and future plans," (ii) "weather," and (iii) "an event/person I can't forget" - and participants were informed of them in advance (2-3 weeks prior to the recording) and allowed to bring keywords with them to help organize their talks. While participants spoke on all three topics in English, they also chose one to speak on in Japanese, thus producing Japanese and English spoken texts on one subject that were conceptually the same. The talks were "free" in that participants created a spoken text constrained solely by their linguistic capacity. Each free talk lasted about two minutes (120 seconds) and the recording was made in a professional studio where participants spoke alone into a microphone in a sound-insulated recording room. ${ }^{2}$

At the time of the recordings, all 25 project participants (J1-J25) of the larger project lived in Kuala Lumpur, the capital of Malaysia. ${ }^{3}$ Five speakers were selected from among them for this analysis, for two reasons. One is that they chose "weather" as the topic of their free talk in Japanese, which enabled the author to compare and contrast English and Japanese texts that were conceptually similar. The other is that the spoken texts on weather were the most homogenous: speakers customarily began with a description of the hot weather in Malaysia, including comparison with the weather in Japan or another country, referring to personal experiences or sharing thoughts about hot or cold weather. Table 1 presents the beginning of each speaker's talk; all of them are concerned with either the heat or the rain considered to characterize the weather in Malaysia. I judged that such

2 They were facing the control room and could make eye contact with people (among whom the author) in the control room.

3 The choice of Malaysia is due to the author's affiliation with a university in Kuala Lumpur. 
homogenous texts would ease analysis and offer quick insights into the general picture of JE.

Table 1. The beginning of the talk produced by five Japanese speakers

\begin{tabular}{|c|l|}
\hline Speaker & \multicolumn{1}{c|}{ The beginning of the talk } \\
\hline J2 & $\begin{array}{l}\text { The weather in Malaysia is very hot and I know some people don't } \\
\text { like the weather, but for me }(0.44)^{4} \text { it's very }(0.5) \text { comfortable to stay } \\
\text { here. }\end{array}$ \\
\hline J3 & $\begin{array}{l}\text { I (0.17) I like summer. (1.26) I like Malaysian weather (0.38) such as } \\
(0.46) \text { hot and }(0.51) \text { rain. (0.96) }\end{array}$ \\
\hline J5 & $\begin{array}{l}\text { So weather, uh (0.59), so about weather in Malaysia. I (0.43), yeah, } \\
\text { it's really hot. It's just hot. (0.71) }\end{array}$ \\
\hline J8 & $\begin{array}{l}\text { About weather, uh (0.67), about Malaysian weather I have three } \\
\text { impression. First is hot, and second is humid and third is, uh (0.51), } \\
\text { heavy rain and thunder clap. }\end{array}$ \\
\hline J12 & $\begin{array}{l}\text { I'm from Sapporo, Hokkaido, where is north part of Japan. (0.91) So, } \\
\text { the weather here is totally different from weather here. The big } \\
\text { difference is rain and thunder. }\end{array}$ \\
\hline
\end{tabular}

In terms of demographics, the five speakers were either Japanese language teachers working for a university or foundation course (J2, J3, and J12) or undergraduate exchange students from Japanese universities (J5 and J8). The participants in the first group rarely had the opportunity to speak in English due to the nature of their job, although they spoke it occasionally (at meetings in the workplace, in conversations outside work). Due to their study program, the participants in the second group used English actively every day, mostly with classmates and roommates. All the participants had started to learn English substantively from the first year of junior high school (Section 1). ${ }^{5}$ These speakers were not stereotypical Japanese citizens, routinely speaking Japanese with little or no exposure to English (Section 1). They had contact with the outside world and made good use of English as a means of communication; interestingly, most of their English communication occurred without the presence of native English speakers. Table 2 summarizes the five speakers' linguistic and social backgrounds as of December 2016 (J2, J3), May 2017 (J5, J8), and June 2017 (J12).

4 The parentheses present the duration of a pause in seconds, which was measured by Praat (Boersma and Weenink 2017). The pauses are given only when they are prominent.

5 A brief note on J5 might be useful since he stayed on Fiji for a year when he was a high school student and went to a local high school. He described this as an unforgettable experience in his third free talk. 
Table 2. Japanese English speakers' linguistic and social backgrounds

\begin{tabular}{|c|c|c|c|c|c|}
\hline $\begin{array}{c}\text { Speaker, } \\
\text { Gender, } \\
\text { Age }\end{array}$ & $\begin{array}{c}\text { Exposure } \\
\text { to native } \\
\text { English }\end{array}$ & $\begin{array}{c}\text { Length of } \\
\text { stay in } \\
\text { Malaysia }\end{array}$ & $\begin{array}{c}\text { Language in } \\
\text { everyday } \\
\text { life }\end{array}$ & $\begin{array}{l}\text { Language } \\
\text { at home } \\
\text { (with the } \\
\text { family }\end{array}$ & $\begin{array}{l}\text { When do I use } \\
\text { English? }\end{array}$ \\
\hline $\begin{array}{c}\mathrm{J} 2 \\
\text { Female } \\
37\end{array}$ & $\begin{array}{l}\text { Recently } \\
\text { completed } \\
2 \text { years of } \\
\text { English } \\
\text { classes }\end{array}$ & 6 years & $\begin{array}{l}\text { - Japanese } \\
\text { - Malay }\end{array}$ & $\begin{array}{l}\text { - Japanese } \\
\text { - English }\end{array}$ & $\begin{array}{c}\text { - Workplace } \\
\text { - Conversation } \\
\text { with Malaysians }\end{array}$ \\
\hline $\begin{array}{c}\mathrm{J} 3 \\
\text { Female } \\
51\end{array}$ & NA & 5 years & $\begin{array}{c}\text { - Japanese } \\
\text { - Occasional } \\
\text { use of } \\
\text { English in } \\
\text { public places }\end{array}$ & - Japanese & $\begin{array}{l}\text { - Limited use in } \\
\text { the workplace }\end{array}$ \\
\hline $\begin{array}{c}\text { J5 } \\
\text { Male } \\
21 \\
\end{array}$ & $\begin{array}{c}\text { Sharing a } \\
\text { flat with an } \\
\text { American }\end{array}$ & 9 months & $\begin{array}{l}\text { - Japanese } \\
\text { - English }\end{array}$ & - Japanese & $\begin{array}{l}\text { - At school } \\
\text { - In the flat }\end{array}$ \\
\hline $\begin{array}{c}\text { J8 } \\
\text { Female } \\
21\end{array}$ & $\begin{array}{c}\text { Had } \\
\text { English } \\
\text { teacher at } \\
\text { school in } \\
\text { Japan } \\
\end{array}$ & 9 months & $\begin{array}{l}\text { - Japanese } \\
\text { - English }\end{array}$ & - Japanese & $\begin{array}{l}\text { - At school } \\
\text { - In the } \\
\text { dormitory }\end{array}$ \\
\hline $\begin{array}{c}\text { J12 } \\
\text { Female } \\
38\end{array}$ & $\begin{array}{l}\text { Stayed in } \\
\text { Wales for } \\
10 \text { months } \\
\text { in } 2004- \\
2005\end{array}$ & 2 years & $\begin{array}{c}\text { - Japanese } \\
\text { - Occasional } \\
\text { use of } \\
\text { English in } \\
\text { public places }\end{array}$ & - Japanese & $\begin{array}{l}\text { - Limited use in } \\
\text { the workplace }\end{array}$ \\
\hline
\end{tabular}

\section{Analyzing free talks}

In analyzing the free talks, lexicogrammatical features typically departing from native English norms were examined carefully. This study follows the principle of Cogo and Dewey (2012) (hereafter C\&D) by regarding non-native features as "innovative language forms" (C\&D: 13) integral to the English produced by JE speakers. In using the term "innovative forms" rather than "learner errors", as did classical scholars for virtually the same type of data (Corder 1967; Selinker 1972), $C \& D$ regard new forms as exhibiting systematic occurrence and organized patterns within the "localized repertoire" (C\&D: 21), ${ }^{6}$ and hence, native Englishes are no longer viewed as the goal of learning and/or a language in international

6 There are concerns about the notion of systematicness. Swan (2012: 386) observed that C\&D described non-native features (e.g. definite article use) but questioned how systematic the occurrences are. 
settings. ${ }^{7}$ Where the present study differs from $C \& D$ is in its consideration of native-norm equivalents of non-native features and their Japanese equivalents. The reason for the first is that, as noted briefly in the Introduction, both non-native and native features co-occur often, if not always, in JE talks. The reason for the second consideration is that the analyzer can better grasp what the speaker has in mind when the same topic is provided in two languages. This process of comparison between Japanese and English talks boosted my understanding of how the participants managed the English language to verbalize their thoughts and ideas. $^{8}$

\subsection{Articles}

The majority of non-native features occurred in the use of articles. Since Japanese has no articles (C\&D: 64), one might argue that errors concerning articles originate from their absence in L1, but this rule of thumb does not generalize to all cases. Rather than choosing articles different from those found in English as a native language (ENL), ${ }^{9}$ participants produced nouns with no article. The noun "weather" frequently occurred with no definite article when it was introduced as the topic of a talk (J5: So, (the) weather, so (the) Malaysian weather; J8: About (the) weather). ${ }^{10}$ Articles were also used inconsistently. J12 produced a sentence consisting of two clauses comparing the weather in Japan and Malaysia: So, the weather there is totally different from (the) weather here. The word weather is accompanied by the in the first clause and appears without it in the second, meaning that the speaker might have known that weather needs the definite article but forgot to include it the second time. There is another problem with the definite article when it comes to general reference. In stating his opinion about hot weather in general, J5 first talked about a memorable stay in Fiji and said that he had chosen that destination because he likes hot weather: And I chose Fiji because Fiji (it) has hot weather. However, he indicated that his opinion about hot weather was changing in Malaysia as he had to walk a long way every morning to get to the bus stop and arrived at the classroom dripping with sweat. He said: But now, after living in Malaysia for like nine month (months), I feel like maybe I don't really like the (Ø) hot weather. Twenty seconds later, he rephrased his opinion: So, maybe I like cold weather now. That cold weather is not preceded by the article and has no reference in the given discourse indicates that he was making a generalization about hot weather by mentioning its opposite. These three

7 Ranta (2018: 251-252), discussing the grammar of ELF, urges the explanation of the exact meaning of innovations.

8 The author consulted a native speaker of English for analysis of non-native features.

9 The term "English as a native language" is used interchangeably with "native form" and "native norm" in this paper.

10 The parentheses give either alternative words replacing non-native features or new words added to the original utterance. These possibilities are not absolute but regarded as alternatives that fit into the uttered expressions by JE speakers. 
examples allow us to infer that he might have known the rule that the article is left out for general reference but didn't follow it consistently, similar to J12. A variable usage of weather with and without the definite article is characteristic of $\mathrm{J} 5$, and is found in the following two examples. J5 said: One thing I find interesting about (the) weather, like, something related to (the) weather. Fortyeight seconds later, in order to conclude his talk, he said the same phrase with the: Something related to the weather. J8 tended to use nouns with the zero article where the is expected: ... I have to stay in (the) library or my class until the rain stop (stops). But $\mathrm{J} 2$ placed the as expected: ... you don't want to go out and try to stay in the house where it's very warm.

Indefinite articles were produced much less frequently than definite articles, in line with C\&D (2012: 98, Table 4.5). The indefinite article was replaced either by the zero article or the definite article. To illustrate, three participants, J2, J5, and $\mathrm{J} 12$, did not use $a$ for T-shirt (J2: I can just wear (a) simple T-shirt; J5: I need to go to school with all sweat (in a really sweaty) T-shirt; J12: Usually, I (only) wear only (Ø) (a) T-shirt at home even in winter). There was a single case in the data set in which first mention of the noun was preceded by the definite article (J8: And actually my college's power supply was cut off by the (a) thunderstorm.

Because of the complexity of the article usage and its variations (cf. C\&D 2012: 62), the above discussion is summarized in Table 3. Note that five types (A-E) in the table are selective with special focus on cases where non-native and native features are put to alternative uses, often by the same speaker. While type E only occurred in J8's talk, it is included as it may be a typical feature of JE. The heading for each type in small capitals is the function of an article in the ENL system.

Table 3. Distributions of articles produced by five JE speakers

\begin{tabular}{|c|c|c|c|c|c|c|c|}
\hline \multirow{4}{*}{ Type } & \multirow{4}{*}{$\begin{array}{c}\text { alternative } \\
\text { usage }\end{array}$} & \multirow{4}{*}{ Examples } & \multicolumn{5}{|c|}{ Speakers } \\
\hline & & & $\mathrm{J} 2$ & $\mathrm{~J} 3$ & J5 & J8 & $\mathrm{J} 12$ \\
\hline & & & \multicolumn{5}{|c|}{ Total uses of articles } \\
\hline & & & 11 & 7 & 14 & 12 & 11 \\
\hline \multirow{3}{*}{ A } & \multicolumn{7}{|c|}{ SPECIFIC REFERENCE } \\
\hline & the unused & $\varnothing$ weather in Malaysia & 1 & 4 & 5 & 5 & 5 \\
\hline & expected & the weather in Malaysia & 6 & & 2 & 1 & 4 \\
\hline \multirow{3}{*}{ B } & \multicolumn{7}{|c|}{ REFERENCE IN THE PHYSICAL ENVIRONMENT } \\
\hline & the unused & in $\varnothing$ library & & & & 3 & \\
\hline & expected & in the library & 1 & & & & \\
\hline \multirow{3}{*}{$\mathrm{C}$} & \multicolumn{7}{|c|}{ GENERAL REFERENCE } \\
\hline & the used & I prefer the hot weather & & 1 & 1 & & \\
\hline & expected & I prefer $\varnothing$ hot weather & 1 & 2 & 3 & 1 & \\
\hline \multirow{4}{*}{$\mathrm{D}$} & \multicolumn{7}{|c|}{ INDEFINITE REFERENCE } \\
\hline & $a$ unused & I wear Ø T-shirt & 1 & & 2 & 1 & 2 \\
\hline & the used & go to the country & 1 & & & & \\
\hline & expected & $\begin{array}{l}\text { I wear a T-shirt; } \\
\text { go to a country }\end{array}$ & & & 1 & & \\
\hline
\end{tabular}




\begin{tabular}{|c|c|c|c|}
\hline \multirow{3}{*}{$\mathrm{E}$} & \multicolumn{3}{|c|}{ FIRST MENTION } \\
\hline & the used & $\begin{array}{l}\mathrm{X} \text { was cut off by the } \\
\text { thunderstorm }\end{array}$ & 1 \\
\hline & expected & $\begin{array}{l}\mathrm{X} \text { was cut off by a } \\
\text { thunderstorm }\end{array}$ & \\
\hline
\end{tabular}

\subsection{Plural formation}

Plural formation is another problem for JE speakers. Like articles, Japanese does not possess the equivalent of the plural marker $-s$ which is added to nouns productively. ${ }^{11}$ Plural forms were correctly applied when they were clearly countable (e.g.four seasons; maple leaves). However, J8 used impression to mean "a point" or "an aspect," but did not pluralize it (J8: I have three impression (points), see Table 1). A similar example comes from J12, who was talking about Malaysians, shopping malls, and restaurants in general terms but did not pluralize them (J12: Then, inside like in shopping mall, restaurant, office, or cinema, freezing). These examples might indicate that the JE speakers distinguished between abstract and concrete nouns in their mind. While points are definitely abstract as they are intangible, shopping malls, restaurants, and offices are tangible. These tangible nouns might have been used without $-s$ because J12 was listing them as general concepts: she did not consider them to be concrete and therefore countable. A similar case is found in J3's talk. When she was referring to events in general, she said: In Malaysia, I can't remember when the event (events) was held (happened). The fact that she did not pluralize event indicates that it was conceptualized as general. The addition of the reinforces the pattern of JE: general reference is signaled by the definite article (see C, Table 3). Back to J12: in her talk about "weather" she used a plural form once, for the noun students. She was talking about her students who visited her in her home town. That she met more than one student is an important piece of information, for it was real event and concrete and, above all, we recognize that students is clearly countable, like seasons. She said: And in March, actually, I went (0.25) back to (0.22) I went (0.31) back to Sapporo and met my students. It follows that when it comes to plural formation in JE talks, the important consideration is apparently whether nouns are conceived of as abstract/general or concrete: the suffix $-s$ tends to be attached to the latter but not to the former.

\subsection{Possessive pronouns}

The frequent absence of the possessive pronoun in JE talks is another feature that deserves attention. When J8 was talking about heavy rain in Malaysia, she said, if

11 Japanese marks some restricted nouns, such as the first person singular pronoun watashi or common nouns such as kodomo "child" and gakusei 'student,' by adding -tachi (watashi-tachi "we"; kodomo-tachi "children"; gakusei-tachi "students"). However, this bound morpheme is not productive. 
I forget the (my) umbrella, referring to her own. When $\mathrm{J} 2$ was talking about why she found the weather in Malaysia comfortable, she said, I don't worry about the (my) clothes and (Ø) shoes and (or) anything (anything else). As discussed in Section 3.2, J12 used my when referring to students she had taught: And in March, actually, I went (0.25) back to (0.22) I went (0.31) back to Sapporo and met my students. It is not clear whether the usage of the possessive pronoun my is explicable by reference to L1, but one aspect that is illuminating is that nouns in J2's Japanese spoken text $\mathrm{t}^{12}$ were zero nouns (i.e. fuku toka kutsu toka "clothes and shoes"), whereas in J12's Japanese text, gakusei "student" was accompanied by the reflexive pronoun jibun "self," clearly expressing the idea of possession. In Japanese, possession is often implicit and hence does not surface, as in J2's case. However, when the speaker underlines the aspect of "ownership," like J12, the possessive pronoun surfaces. That is, the native form my is realized when the speaker feels strongly that someone or something belongs to or is connected with him or her. Clothes, shoes, or umbrella do not impart the same level of ownership.

\subsection{Assigning different lexical meaning}

An innovative usage of word meaning is to change the original meaning slightly to make it suitable for a specific context or situation. For example, J3 used the verb recognize to express the meaning understand when she wanted to say that her destination can be deduced based on the clue of a specific season related to a specific event (nobody can recognize (work out) when I went there). J8 used acceptable to mean that she can tolerate or get used to the heat and humidity in Malaysia, and impression to mean "point" or "aspect" (Ah, for the first and second impression (points/aspects), hot and humid, it was acceptable (okay) for me) (see Section 3.2). An interesting contrast was found in J5's usage of remember and recall. When $\mathrm{J} 5$ moved to the second subtopic of his talk (i.e. the cultural relationship between seasons and events), he started to use recall to mean remember. For an ENL speaker, remember and recall are synonymous but differentiated through formality. In J5's talk, the two verbs were also synonymous but differentiated contextually. Remember was used as a neutral verb to describe what he considered to be a general situation (Then (Ø) I will (Ø) remember, like, ah, it was cold, and I was wearing a jacket and I was eating this kind of food) and recall was apparently used to emphasize difficulty: when there is only one season and there is no link between seasons and events, one cannot remember as easily (So, it's really hard to recall (remember) the past).

12 J8 was excluded here because she did not talk about forgetting of her umbrella in her Japanese talk. 


\subsection{Using adjectives in place of nouns}

This section discusses the use of hot as a noun in place of heat. Violation of the system of lexical categories is a feature which Suenobu (1990: 261) listed as a typical L1 transfer. Note, however, that although J12 used the adjectives hot and cold as nouns in English (J12: Malaysian is (Malaysians are) strong to both hot and cold (tolerate the heat and the cold)), in her Japanese talk, she used derived nouns, namely, atsusa "the heat" and samusa "the cold," meaning that the nominal use of hot and cold may not, strictly speaking, be L1 transfer. Something similar can be seen in J8's talk: she had in mind a nominal expression in her Japanese text when she said atsui to iu koto "the fact that it is hot," referring to one of three features of Malaysian weather, but in her English talk, she simply said: First is hot (the heat). Comparison of their texts in English and Japanese suggests that, conceptually, these two speakers had a nominal expression at their disposal but did not end up with the heat when they spoke in English. Although the idea of L1 transfer may not be excluded completely, the use of adjectives as nouns may signal the presence of more than one language in the mind of JE speakers, or put differently, the speaker's knowledge about the target language might influence its production. It is possible that J8 and J12 simply did not know the nominal form of hot. J24 used hotness preceded by the definite article to express to the same meaning. He knew the nominal form of hot.

\subsection{Personal pronouns}

One example that might have been influenced by $\mathrm{L} 1$ is the use of human being, as in J3's talk (but I think the (Ø) we, human being (human beings), have always overcome, uh, winter). An ENL speaker might simply have used we without human beings; the addition could be considered redundant or excessively formal. When J3 spoke in Japanese, she used the equivalent expression watashi-tachi ningen "we, human beings," an addition which native Japanese speakers would not consider excessively formal. Use of ningen "human being" underlines that J3 was talking generally, while the pronoun watashi-tachi "we," when it stands alone, does not directly impart collective meaning. J3's use of human being may be categorized, at first glance, as a prime example of L1 transfer, but it can also demonstrate, similar to Section 3.5, the presence of more than one language in J3's mind. That is to say, we, as used in her English talk, may not be, strictly speaking, a marker of collectivity, but simply an expression of the first person plural marker. This usage may also have derived from J3's knowledge of the target language. J13 and J14 used $m e$ as a collective marker (J13: So, the story (stories) he gave (told) me (us) sounded really interesting; J14: He gave (taught) me (us) 
some kind of lecture (various courses)). ${ }^{13}$ This fact indicates that we is interchangeable with $m e$ in JE spoken discourse and its collectivity may be much weaker than the native-English counterpart.

\subsection{Relative pronouns}

Talking about "weather," with the exception of $\mathrm{J} 12$, who used where once in place of which, the five JE speakers did not use any relative pronouns. J12's use appeared in the first sentence of her talk (see Table 1): I'm from Sapporo, Hokkaido, where (which) is (in the) north part of Japan. While J12 used which to modify "course" and "organization" in her talk about "my current situation and future plans," 14 she apparently knew how to use this pronoun following the native norm, and her use of where represents an alternative usage. In J12's mind, places might be treated differently from objects such as "course" or "organization," since Sapporo is clearly the name of a place and the choice of where would make sense, while it does not for the other two nouns. In my entire data set, this usage of where occurs only once but it indicates that where is emerging as another relative pronoun besides which in JE's grammar.

\subsection{Coreference}

JE speakers tend to repeat the same noun within the same sentence, while the noun is coreferenced by the pronoun in a separate sentence. A neat pair of examples come from J5. Talking about his one-year stay in Fiji, he said: And I chose Fiji because Fiji (it) has hot weather. An ENL speaker would use the pronoun it to avoid repetition of Fiji. This non-native usage does not mean that J5 did not know the rule of coreference, as he made good use of it in the next sentence: So, I used to really love it. The pronoun it refers to hot weather, the theme of his free talk. The same kind of repetition was produced by $\mathrm{J} 2$ when she said at the beginning of her talk (see Table 1): The weather in Malaysia is very hot and I know some people don't like the weather (it). There was no coreferential usage of it in her talk comparable to J5's.

\subsection{Overdoing explicitness}

This is a notion originally introduced by Seidlhofer (2004), quoted by C\&D (2012: 48), to categorize examples such as black color instead of black. In my data set, one example that fits this category is winter season. $\mathrm{J} 2$ and $\mathrm{J} 3$ both produced this expression in their talks: the season "winter" was characterized as having a low

$13 \mathrm{~J} 24$ (Section 3.5) and J13 and J14 (Section 3.6) were the participants not included in the paper. Additional examples produced by these speakers were offered here to strengthen the arguments in both sections.

14 I am referring to another talk by $\mathrm{J} 12$ to offer examples. 
temperature causing coldness. Neither speaker liked the cold, especially because they had been in Malaysia for some time and had become comfortable with the hot weather. As shown in the following examples, J2 and J3 used winter season where winter was expected.

J2: So since, since I, since I, since I (have) got used to Malaysia with the hot weather, I don't want to go to the (a) country, uh, which has, uh uh winter season (winter).

J3: I don't like (the) winter season but I think we need winter season (winter) (1.83) to (2.0) appreciate (2.19) spring or summer.

In her Japanese equivalent of the same utterance, J2 used fuyu no kisetsu ("winter season") but J3 did not. Moreover, as shown by the example below, which was said after the above example, J3 used winter alone in her talk in English. Why didn't she use winter season?

J3: I think it is too exaggerate (much of an exaggeration), but I think the (Ø) we, human being (human beings), have always overcome, uh, winter.

On closer look, we note that the meaning of winter is reduced in this utterance; that is, winter may not be understood as representing the cold but a season. Recall Crystal's (2010) earlier assertion (Section 1). I interpret winter season, as used here, as representing cultural knowledge about winter shared collectively by Japanese people, which is that it is typically cold and severe in contrast to the other three seasons. To express this cultural knowledge, speakers created a new variant, winter season, without losing the ENL form winter. This usage shows how culture is embodied in non-native spoken discourse, what C\&D dubbed "localized repertoire." The choice of season might have derived from L1, since Japanese allows the same expression but its usage in L2 may not be a direct reflection of L1.

\section{Conclusion}

This paper has presented a preliminary analysis of lexicogrammatical features extracted from recorded free talks on the topic of "weather" in English and Japanese produced by five native Japanese speakers aged 21 to 51 . All these speakers had a similar educational background in Japan, beginning to learn English at school. At the time of the recording, they had opportunities to use the language in Malaysia. Against this sociolinguistic background, the analysis of the data (Section 3), the heart of this paper, has demonstrated how some new variants, or what C\&D called "innovative language forms," came into existence. This study has identified coexisting alternatives, so to speak, to native forms which, in some cases, carried specific meanings/functions which were largely individual-based and arose on the fly in spoken discourse. 
Since Honna and Takeshita's (1998) paper on JE in the first volume of Asian Englishes, there have been calls for a paradigm shift in foreign language education in Japan, a shift that would promote an indigenous Japanese usage of the English in place of native English norms in the spirit of Kachru (2017: 148). Concomitantly, the focus of this research direction has been on criticism of "native-speakerism" (Houghton and Rivers 2013), or "Japan's propensity for native speaker English," to borrow Honna and Takeshita's (1998) expression. The stance taken by the present paper is essentially the same as Honna and Takeshita's in that I seek to define JE as a variety owned by its users and existing independent of native English - and this conception is accurate given the fact that JE speakers have few opportunities for contact or communication with ENL speakers. Besides this, the description of features, as undertaken above, should also contribute to defining an emerging variety and it is hoped that this paper is a step in this direction. Considering the fact that JE is essentially learned - it originates from formal education in a context in which English is not a language of daily communication - it can be concluded that innovative linguistic forms in JE develop from the speaker's L1 and his or her knowledge, albeit basic, of the native norm, the norm learners are taught in the classroom. This paper has illustrated the robustness of multiple knowledge possessed by JE speakers as L2 users. On a broader scope, this is what Cook (2016: 3) has defined as "multi-competence," "the overall system of a mind" which L2 users have at their disposal in handling two languages, and Mackenzie (2016: 494) sees ELF (English as a lingua franca) as an instantiation of multi-competence. Turning to the teaching of English (Section 1), I take the position, for now, that standard English - or, better, pedagogical core English - is the form of the language which Japanese people should learn as an input language, supplemented by non-native features, as discussed above, that draw on the "real-world phenomenon" (Jenkins 2018: 599) we experience in our lives - and from here we may be able to scrutinize the processes or features involved in shaping an output language.

One final point concerns Swan's (1985) prediction, quoted at the outset, of the rise of a new international language whose lexicogrammatical structure may be simplified. What we have discussed in this study turns this proposition on its head. The creation of alternative forms, if it continues, will definitely add to the structure of this new language.

\section{References}

Abe, Emiko. 2013. Communicative language teaching in Japan: current practices and future prospects. English Today 29 (2). 46-53.

Boersma, Paul and David Weenink. 2017. Praat: doing phonetics by computer (Version 6.0.40) [computer software]. Available from: http://www.praat.org/

Browne, Charles M. and Minoru Wada. 1998. Current issues in high school English teaching in Japan: an exploratory survey. Language, Culture and Curriculum 11 (1). 97-112. 
Cogo, Alessia and Martin Dewey. 2012. Analysing English as a Lingua Franca: A Corpus-driven Investigation. London/New York: Continuum.

Cook, Vivian. 2007. The goals of ELT: Reproducing native-speakers or promoting multicompetence among second language users? In

Corder, Stephen Pit. 1967. The significance of learners' errors. International Review of Applied Linguistics 5. 161-170.

Crystal, David. 2010. The future of Englishes: going local. In: Roberta Facchinetti, David Crystal and Barbara Seidlhofer (eds.), From International to Local English - And Back Again, 17-25. Bern: Peter Lang.

D'Angelo, James F. 2018. The status of ELF in Japan. In: Jennifer Jenkins, Will Baker and Martin Dewey (eds.), The Routledge Handbook of English as a Lingua Franca, 165-175. London: Routledge.

Friedman, Jeffrey. 2016. English education in the era of Meiji Japan. World Englishes 35 (1). 3-17.

Honna, Nobuyuki and Yuko Takeshita. 1998. On Japan's propensity for native speaker English: a change in sight. Asian Englishes 1 (1). 117-134.

Houghton, Stephanie Ann and Damian J. Rivers. 2013. Native-speakerism in Japan: Intergroup Dynamics in Foreign Language Education. Bristol: Multilingual Matters.

Jenkins, Jennifer. 2018. The future of English as a lingua franca? In: Jennifer Jenkins, Will Baker and Martin Dewey (eds.), The Routledge Handbook of English as a Lingua Franca, 594-605. London: Routledge.

Kachru, Braj. 2017. World Englishes and Culture Wars. Cambridge: Cambridge University Press.

Mackenzie, Ian. 2016. Multi-competence and English as a lingua franca. In: Vivian Cook and Li Wei (eds.), The Cambridge Handbook of Linguistic Multi-competence, 478-501. Cambridge: Cambridge University Press.

McKenzie, Robert M. 2008. The complex and rapidly changing sociolinguistic position of the English language in Japan: a summary of English language contact and use. Japan Forum 20 (2). 267-286.

McKenzie, Robert M. 2013. Changing perceptions? A variationist sociolinguistic perspective on native speaker ideologies and Standard English in Japan. In: Stephanie Ann Houghton and Damian J. Rivers (eds.), Native-speakerism in Japan: Intergroup Dynamics in Foreign Language Education, 219-230. Bristol: Multilingual Matters.

Ranta, Elina 2018. Grammar in ELF. In: Jennifer Jenkins, Will Baker, and Martin Dewey (eds.), The Routledge Handbook of English as a Lingua Franca, 244-254. London: Routledge.

Seargeant, Philip (ed.). 2011. English in Japan in the Era of Globalization. Basingstoke: Palgrave Macmillan.

Seidlhofer, Barbara. 2004. Research perspectives on teaching English as a lingua franca. Annual Review of Applied Linguistics 24. 209-239.

Selinker, Larry. 1972. Interlanguage. International Review of Applied Linguistics 10. 209-241.

Smith, Donald L. 2004. Review of Japanese English: Language and Culture Contact (James Stanlaw). Asian Englishes 7 (2). 126-132.

Stanlaw, James. 2014. Japanese English: Language and Culture Contact. Hong Kong: Hong Kong University Press.

Strevens, Peter. 1992. English as an international language: directions in the 1990s. In: Braj B. Kachru (ed.), The Other Tongue, 27-47. Urbana/Chicago: University of Illinois Press.

Suenobu, Mineo. 1990. Nihon Eigo [Japanese English]. In: Nobuyuki Honna (ed.), Ajia no Eigo [Varieties of English in Asia], 257-286. Tokyo: Kuroshio.

Swan, Michael. 1985. Where is the language going? English Today 3. 6-8.

Swan, Michael. 2012. ELF and EFL: are they really different? Journal of English as a Lingua Franca 1-2. 379-389.

Tsuboya-Newell, Ikuko. 2017. Why do Japanese have trouble learning English? The Japan Times. [Online] 29th October. Available from: https://www.japantimes.co.jp/opinion/2017/10/29/ 
commentary/japan-commentary/japanese-trouble-learning-english/.

[Accessed: 17th April 2018].

Tsuneyoshi, Ryoko. 2013. Communicative English in Japan and "Native speakers of English." In: Stephanie Ann Houghton and Damian J. Rivers (eds.), Native-speakerism in Japan: Intergroup, Dynamisms in Foreign Language Education, 119-131. Bristol: Multilingual Matters.

Yamaguchi, Toshiko and Magnús Pétursson. 2018. Japanese English: Norm-dependency and emerging strategies. English Today 34 (2). 17-24. 